\title{
Gestão democrática $X$ desempenho no ENEM: um estudo em escolas da capital do Amapá
}

\author{
Letícia Uane Avis de Oliveira ${ }^{1}$, Alan Carlos Pereira Costa ${ }^{1}$, \\ Gustavo Magno de Oliveira Ubirajara ${ }^{1}$ e Cláudio Márcio Campos de Mendonça ${ }^{1}$
}

1 Universidade Federal do Amapá

RESUMO: O presente artigo investigou a influência da Gestão Escolar democrática no desempenho dos alunos de escolas públicas em Macapá/AP no Exame Nacional do Ensino Médio (ENEM). Com base nisso, o artigo teve como objetivo geral comparar os modelos de gestão das melhores e piores escolas de uma capital da região amazônica de acordo com o ranking do ENEM, de acordo com 4 elementos da gestão democrática. Para tanto, foi elaborado um instrumento de coleta de dados utilizando questões com enfoque em participação, autonomia e transparência, e posteriores entrevistas com os gestores das escolas públicas que obtiveram melhores e piores desempenhos no Exame. Os resultados obtidos na pesquisa evidenciam que a Gestão Escolar influencia de maneira positiva no desempenho dos alunos e nas suas respectivas notas no ENEM, sendo que as escolas com as notas mais elevadas apresentam maiores níveis de participação e transparência.

Palavras-chave: Gestão escolar; Gestão democrática; Desempenho educacional; ENEM.

Democratic management $X$ performance in the ENEM:

a study in schools of the capital of Amapá

ABSTRACT: This current article investigated the influence of school democratic management on the performance of public school students in Macapá-AP that carried out the national high school examination (ENEM). Based on these studies, the article had as the general goal to compare the management models of the best and worst schools in a capital of the Amazon region according to the ranking of ENEM, based on 4 elements of democratic management, an instrument of data collection was developed using issues with a focus on participation, autonomy, transparency and subsequent interviews with managers of public school who had better and worse performances in the examination. The results obtained in the research, show that the School Management has a positive influence on the performance of the students and in their respective notes in the ENEM, being that the schools with the highest grades show greater levels of participation and transparency.

Keywords: School Management, Democratic Management, Educational Performance, ENEM.

\section{INTRODUÇÃO}

Dentre os desafios atuais para a educação no Brasil, encontra-se o de como meIhorar a qualidade do seu ensino e quais são fatores que contribuem e influenciam no desempenho do aluno no âmbito escolar. Para tanto, tem sido analisada a relação entre gestão escolar democrática e o desempenho do aluno em escolas públicas com base nas notas obtidas no Exame $\mathrm{Na}$ cional do Ensino Médio (ENEM).

O número de participantes no ENEM aumenta gradativamente desde a sua criação em 1998, e com isso, o reconhecimento do exame como importante ferramenta 
avaliativa. O ENEM foi escolhido como forma de análise de desempenho escolar, onde se pretende verificar o impacto e a influência da gestão escolar no desempenho dos alunos nas escolas públicas.

Atualmente, o ENEM tem sido utilizado como a principal forma de ingresso em Instituições de Ensino Superior, portanto, percebe-se que a atenção dada ao planejamento e preparação para a realização da prova, tem mudado os mecanismos de elaboração dos conteúdos programáticos, por meio de aulas diversificadas e projetos voltados à melhoria das notas no ENEM, oriundos de uma das estratégias da gestão democrática.

A gestão democrática está prevista na $L D B$, que diz que os sistemas de ensino deverão definir as normas para a implementação e manutenção da mesma, observando alguns princípios como participação de profissionais da educação e da comunidade escolar nas atividades e decisões da escola.

A escola é responsável pela promoção do desenvolvimento da cidadania aos alunos, no sentido de formar e capacitar cidadãos conscientes, capazes de compreender e criticar a realidade, repassando conhecimentos práticos e teóricos a serem utilizados no dia-a-dia.

Desse modo, Luck (2009) argumenta que a gestão escolar pode ser definida como o ato de gerir a dinâmica cultural da escola, dentro das políticas e diretrizes educacionais para a implementação do Projeto Político Pedagógico-PPP, além de observar a democracia e a criação de condições para um ambiente escolar autônomo, participação, compartilhamento, acompanhamento e avaliação de resultados.

$\mathrm{O}$ desempenho médio por escola no $\mathrm{E}$ NEM, não é suficiente para realizar uma boa comparação da qualidade de ensino presta- da pelas escolas públicas. Todo resultado de avaliação representa o produto da interação de um conjunto de fatores, dentre eles a gestão escolar democrática e as práticas de ensino voltadas para o ENEM exercidas na escola.

O gestor escolar tem papel fundamental dentro da instituição de ensino, sendo o articulador na organização de um ambiente de participação para o desenvolvimento e desempenho dos alunos no processo pedagógico.

A abordagem deste artigo é evidenciar a importância da gestão democrática e suas práticas na construção de um ambiente favorável ao ensino aprendizagem, em busca de caminhos inovadores para melhorar a qualidade de ensino prestado, e consequentemente aumentar o desempenho dos alunos no ENEM. Portanto o artigo teve como objetivo comparar os modelos de gestão das melhores e piores escolas de uma capital da região amazônica de :acordo com o ranking do ENEM, com base nos 4 elementos da gestão democrática.

Este trabalho estrutura-se em cinco etapas, sendo elas: introdução, onde será apresentada uma visão geral sobre o tema, o objetivo e a importância deste artigo; referencial teórico, onde será abordado um histórico sobre as temáticas apresentadas, conforme os autores da literatura; metodologia; análise de resultados e considerações finais.

\section{REFERENCIAL TEÓRICO}

\subsection{GESTÃO ESCOLAR}

Os princípios e métodos presentes na organização escolar originam-se de um conjunto de experiências anteriores em diver- 
sos tipos de organizações. Porém, para a escola, a gestão deve ter seus objetivos voltados para a educação e formação de pessoas, possuindo diversas características diferenciadas de outras práticas de gestão anteriores (MARTINS, 2015).

Segundo Freitas (2007), o conceito de gestão escolar teve origem no momento de crítica ao "caráter conservador e autoritário" da administração escolar para demonstrar seu compromisso com as mudanças sociais e com a consequente democratização do ensino e da escola.

De acordo com Vieira (2007) explica a diferença entre os conceitos de gestão pública e gestão educacional, esclarece que a abrangência dos estabelecimentos de ensino remete-se à gestão escolar, enquanto o espaço das ações de governo situa-se à gestão educacional.

Com uma proposta inovadora de gestão escolar, a legislação educacional brasileira propõe que a escola pública se utilize da gestão democrática como meio de garantir a participação de diversas perspectivas da sociedade no processo educativo. Desse modo, há de se repensar as estruturas e relações de poder presentes no ambiente escolar para possibilitar esse tipo de gestão (CABRAL; SOUSA; NASCIMENTO, 2015).

Conforme sugere Libâneo (2004) o diretor é o principal encarregado de dirigir e responsabilizar-se pela escola, devendo ter a visão do conjunto, de modo a articular e integrar os vários setores que a abrangem. Segundo Koetz (2010), ao diretor, compete, ainda, buscar mecanismos que possibilitem a superação dos obstáculos, a maioria decorrentes da própria estrutura e organização dos sistemas de ensino e das instituições, do mesmo modo que dos conflitos ocasionados pela diversidade cultural pre- sente no cotidiano escolar.

Ainda em relação à figura do diretor, Luck (2009) contribui argumentando que o diretor é líder, mentor, o principal gerenciador da vida da escola e suas responsabilidades não pode ser dividida entre outros colaboradores da gestão, podendo ser com eles compartilhada. Assim, cabe ao diretor a responsabilidade maior sobre a gestão escolar, devendo este ter um papel de zelo pela escola como um todo.

\subsection{GESTÃO DEMOCRÁTICA}

De acordo com Silva e Sacramento (2015) argumentam quando uma escola adere uma gestão escolar democrática, possibilita dessa forma a participação efetiva de todos os atores da comunidade escolar, trazendo significativas contribuições tanto para o processo de formação do aluno, quanto para melhorias no âmbito da escola. Nesse sentido, a gestão escolar deixa ser caracterizada como centralizadora que concentra as decisões na figura de um diretor ou coordenador e passa a ser mais integradora.

Porém, ao se estabelecer uma gestão que tem como princípio a participação de diversos atores nas decisões e compartiIhamento das responsabilidades sobre o processo educacional, requer tanto mudanças externas como mudanças internas no interior da escola que podem gerar certos confrontos de opinião acerca da forma de organização e liderança que será a mais adequada para contribuir no processo educacional (CABRAL; SOUSA; NASCIMENTO, 2015).

Nesse sentido, a adoção de uma gestão democrática necessita de uma quebra de paradigmas dos atores que serão influenci- 
ados nesse processo, pois terão que se responsabilizar de atuar com contribuições para o desenvolvimento da escola.

A gestão democrática está prevista na Constituição Federal e na LDB, e sua construção passa pela garantia de alguns princípios fundamentais como: participação política; a coordenação, planejamento e a descentralização dos processos de decisão e de execução e o fortalecimento das unidades escolares; a elaboração coletiva de diretrizes gerais; a universalização da educação básica e a gratuidade do ensino (DOURADO, 2012).

Em relação aos princípios norteadores da gestão democrática na escola pública, a LDB dispõe do Art. 14, que atribui aos sistemas de ensino à responsabilidade de definir as normas da gestão democrática no ensino público da educação básica, levando em consideração as peculiaridades de cada sistema de ensino e atentando para participação dos profissionais da educação na elaboração do Projeto Político-Pedagógico da escola e participação das comunidades escolar e local por meio de conselhos escolares ou equivalentes, conforme artigo citado (BRASIL,2016).

\subsubsection{ELEMENTOS DA GESTÃO DEMOCRÁ- TICA}

A Constituição Federal estabelece no artigo 206, os princípios sobre os quais o ensino deve ser ministrado, dentre eles destaca-se a gestão democrática do ensino público (BRASIL, 1988).

Art. 206 - O ensino será ministrado com base nos seguintes princípios:

I - igualdade de condições para o acesso

e permanência na escola;
II - liberdade de aprender, ensinar, pesquisar e divulgar o pensamento, a arte e 0 saber;

III - pluralismo de ideias e de concepções pedagógicas, e coexistência de instituições públicas e privadas e privadas de ensino;

IV - gratuidade do ensino público em estabelecimentos oficiais;

(...)

$\mathrm{VI}$ - gestão democrática do ensino público, na forma da lei;

A Lei de Diretrizes e Bases (LDB), em seus artigos 14 e 15, apresentam as seguintes determinações a respeito da gestão democrática (BRASIL, 2010):

Art. 14 - Os sistemas de ensino definirão as normas da gestão democrática do ensino público na educação básica, de acordo com as suas peculiaridades e conforme os seguintes princípios:

Participação dos profissionais da educação na elaboração do projeto pedagógico da escola;

II. Participação das comunidades escolar e local em conselhos escolares ou equivalentes.

Art. 15 - Os sistemas de ensino assegurarão às unidades escolares públicas de educação básica que os integram progressivos graus de autonomia pedagógica e administrativa e de gestão financeira, observadas as normas de direito financeiro público.

Os artigos da LDB citados, dizem que a "gestão democrática do "ensino público na educação básica" aos sistemas de ensino, oferece ampla autonomia às unidades federadas para definirem em sintonia com suas especificidades formas de operacionalização da gestão, com a participação dos pro- 
fissionais da educação envolvidos e de toda a comunidade escolar e local" (VIEIRA, 2005, p.64).

Para Araújo (2000), os elementos constitutivos dessa forma de gestão são apontados em quatro elementos como a participação, autonomia, transparência e pluralidade. E como instrumentos de sua ação, surgem as instâncias diretas e indiretas de deliberação, tais como conselhos e similares, que propiciam espaços de participação e de criação da identidade do sistema de ensino e da escola. Assim, a gestão democrática da educação.

Para melhor compreensão, serão apresentados mais detalhadamente os quatro elementos da gestão democrática:

\section{a. Participação:}

Segundo os estudos de Bordignon e Gracindo (2000), a participação escolar é identificada como um simples processo de colaboração, adesão e de obediência às decisões da direção da escola. Tais decisões são tomadas previamente e os objetivos da participação também são delimitados antes dela ocorrer.

A participação é o principal meio de se assegurar a gestão democrática da escola, possibilitando o envolvimento de profissionais e usuários no processo de tomada de decisões e no funcionamento da organização escolar. Além disso, proporciona um melhor conhecimento dos objetivos e metas, da estrutura organizacional e de sua dinâmica, das relações da escola com a comunidade, e favorece uma aproximação maior entre professores, alunos e pais (LIBÂNEO, 2004, p.79).

\section{b. Transparência}

Segundo Mendes (2001), o conceito de transparência tem a importante função de disponibilizar subsídios para análise acerca das finanças públicas, o que fornece uma maior fiscalização das contas públicas por parte da sociedade. Conclui que a busca pela transparência é a busca pela legitimidade. Brasil (2000) estabelece que:

Art. 48. São instrumentos de transparência da gestão fiscal, aos quais será dada ampla divulgação, inclusive em meios eletrônicos de acesso ao público: os planos, orçamentos e leis de diretrizes orçamentárias; as prestações de contas e o respectivo parecer prévio; o Relatório Resumido da Execução Orçamentária e o Relatório de Gestão Fiscal; e as versões simplificadas desses documentos. Parágrafo único: A transparência será assegurada também mediante incentivo à participação popular e realização de audiências públicas, durante os processos de elaboração e de discussão de planos, lei de diretrizes orçamentárias e orçamentos.

De acordo com Araújo (2000), a transparência demonstra a dimensão política da escola. A partir de sua existência é gerada a construção de um espaço público forte e suscetível às diversidades de opiniões e concepções do mundo, abrangendo a participação de todos que de alguma forma podem interagir com a escola.

Para Cury (1997), a transparência presume a existência de um espaço público e aberto; no entanto, os fundamentos do mercado são pautados por interesses imediatistas e particulares, pelo anseio de lucro, predominando, então, o poder das cúpulas, ou de grupos específicos, que nem sempre têm a preocupação de prestar contas ou 
dar satisfação do que é feito ao conjunto da população.

\section{c. Pluralismo}

O pluralismo, segundo Araújo (2000), consolida-se como forma de reconhecimento da inerente existência de diferenças de identidade e de interesses que compõem o interior da escola e que sustentam, por meio do debate e do conflito de ideias, o próprio sistema democrático.

Segundo Touraine (1996), a essência do pluralismo democrático consiste no respeito aos projetos individuais e coletivos. A democracia não pode ser definida pela participação, nem pelo consenso, e sim pelo respeito às diversidades e à liberdade. De acordo com Bobbio (2000), quanto mais repartido for o poder, melhor governada será e quanto mais numerosos forem os centros de poder que administram e controlam os órgãos do poder central.

\section{d. Autonomia}

Segundo Brasil (2010, p.4), em seu Art. 15 , "os sistemas de ensino assegurarão às unidades escolares públicas de educação básica que os integram progressivos graus de autonomia pedagógica e administrativa e de gestão financeira, observadas as normas de direito financeiro público". Dessa maneira as escolas devem ter certos níveis de autonomia de seus sistemas, nas áreas indicadas pela lei citada. Nesse sentido, Kloh (2011) argumenta que a autonomia escolar na gestão democrática se dá sob três aspectos:

- Autonomia pedagógica: no sentido da liberdade na elaboração de políticas pedagógicas e metodológicas;
- Autonomia Administrativa: no sentido de que uma vez democrática, envolvendo a participação de pais, comunidade escolar e profissionais da educação, a gestão escolar necessita ter liberdade para executar as decisões tomadas pela gestão.

- Autonomia de gestão financeira: no sentido que os sistemas devem escoIher onde melhor aplicar os recursos financeiros.

Porém, Oliveira, Moraes e Dourado (2008) colocam que há vários fatores que dificultam essa autonomia pedagógica, administrativa e financeira, como: centralização de decisões, entraves à implementação dos princípios de gestão colegiada, PPP restrito apenas ao atendimento das determinações de secretarias de educação e a forma de provimentos dos cargos de dirigentes escolares.

\subsection{ENEM}

O Exame Nacional do Ensino Médio, ENEM, foi criado em 1998 pelo Ministério da Educação, com o objetivo de avaliar o desempenho dos egressos da educação básica, buscando contribuir para a qualidade da educação desse nível de escolaridade (MEC, 2014).

Segundo o MEC, o exame tem como função auxiliar a escola em construir o conhecimento do aluno, desenvolvendo capacidades de aprender, criar, formular, ao invés do simples exercício de memorização (MEC, 2000). O ENEM tem a finalidade de avaliar o desempenho do estudante no término do ensino médio, visando aferir o desenvolvimento das competências e habilidades necessárias para o exercício pleno da cidadania (ANDRIOLA, 2011). 
Em 2009, a nota do Enem, além de ser utilizada para verificar o perfil do egresso e a qualidade da educação básica, passou a ser utilizada como mecanismo de seleção para o ingresso no ensino superior. Para tal, foram implementadas mudanças no exame para contribuir com a democratização das oportunidades de acesso às vagas oferecidas pelas Instituições Federais de Ensino Superior (IFES). O Enem também é utilizado como critério de seleção para o acesso a programas oferecidos pelo governo federal, como o PROUNI, FIES, e também oportuniza o ingresso ao ensino técnico, por meio do PRONATEC (MEC, 2014).

Castro e Tiezzi (2004) argumentam sobre a importância do Enem, pois permite ao poder público dimensionar e localizar as lacunas que dificultam o processo de formação dos estudantes e que possam de alguma forma atrapalhar a sua inserção no processo de produção da sociedade, mas também sua realização pessoal. Com isso, o Estado dispõe de um exame para verificar onde o ensino é falho e tomar medidas para garantir a qualidade do ensino na educação básica.

\section{METODOLOGIA}

A pesquisa é uma construção de conhecimento original, conforme determinadas exigências cientificas, e para isso são necessários que critérios como: coerência, consistência, originalidade e objetivação sejam obedecidas. Para atender esses critérios é preciso que na metodologia sejam descritos o tipo de pesquisa, o universo e a amostra, o método e o instrumento de coleta de dados, bem como os métodos estatísticos para análise dos resultados (SILVA; MENEZES, 2005). Levando em consideração o objetivo da pesquisa, buscou-se o caminho para a resolução da questão. Inicialmente, utilizouse da pesquisa exploratória e descritiva. Segundo Mattar (2001), a pesquisa exploratória pode contribuir de forma significativa ao pesquisador, fazendo-o entender de uma forma mais fácil as várias opções aplicáveis ao seu problema de pesquisa. Com relação à pesquisa descritiva, Cervo e Bervian (1996) definem que busca correlacionar fatos ou fenômenos (variáveis).

Portanto, o presente estudo se caracterizou como exploratório e descritivo, sendo fruto do desenvolvimento de uma análise qualitativa realizada em 6 escolas públicas uma capital da região amazônica do Brasil. A pesquisa teórica possibilitou a construção de um instrumento de coleta de dados semiestruturados, divididos da seguinte forma: participação, autonomia e transparência.

Com a utilização das categorias iniciais foi possível a aplicação de uma entrevista semiestruturada, que serviu de elemento norteador da investigação que foi desenvolvida de forma que os entrevistados, gestores principais das escolas públicas, pudessem realizar o seu discurso com detalhamentos sobre suas percepções sobre os itens questionados. Foram realizadas 6 entrevistas com os gestores (diretores) de todas as 6 escolas, também entrevistas com 6 professores para validar as informações repassadas pelos gestores. As entrevistas foram realizadas entre os meses de novembro e dezembro de 2016. Os gestores estão identificados na análise e interpretação dos dados de acordo com a colocação das escolas apresentada no Quadro 1 e Quadro 2, sendo utilizada a estrutura " $E+n$ ", onde " $E$ " representa a palavra entrevistado e " $n$ " a colocação da escola nos quadros citados: E1 
para a primeira colocada, E2 para a segunda, seguindo essa ordem até chegar na E6 que corresponde a última escola do Ranking Estadual no ENEM.

Após a realização das entrevistas foi feita a transcrição literal das entrevistas, dos quais através de uma análise do discurso, que segundo Fernandes (2008), visa colocar o próprio discurso como objeto de estudo, e a partir desse ponto, foi possível comparar os modelos de gestão com base nos quatro elementos da gestão democrática.

Foram escolhidas escolas do Estado do Amapá, no município de Macapá que participaram das últimas 3 edições do ENEM (2013, 2014 e 2015) e que se encaixassem nos seguintes critérios: dependência administrativa (estadual), localização (urbana), porte da escola (maior que 90 alunos) e número de participantes na última edição do ENEM (maior que 90 alunos). Desse modo, a composição do quadro comparativo das escolas é a seguinte:

Quadro 1- Ranking com as escolas públicas com melhores notas no ENEM 2015

\begin{tabular}{|l|c|}
\hline Escola & Média Geral \\
\hline Esc. Est. Tiradentes & 501,503 \\
\hline Esc. Est. Prof. Gabriel Almeida Café (CCA) & 491,070 \\
\hline Esc. Est. Dr. Alexandre Vaz Tavares (AVT) & 489,564 \\
\hline
\end{tabular}

Fonte: Mec, 2016 (Adaptado)

Quadro 2- Ranking com as escolas públicas com menores notas no ENEM 2015

\begin{tabular}{|l|c|}
\hline Escola & Média Geral \\
\hline Esc. Est. Prof. Nilton Balieiro Machado & 466,664 \\
\hline Esc. Est. Maria do Carmo Viana Dos Anjos & 464,929 \\
\hline $\begin{array}{l}\text { Esc. Est. Profa Maria Cavalcante de Azeve- } \\
\text { do Picanço }\end{array}$ & 459,480 \\
\hline
\end{tabular}

Fonte: Mec, 2016 (Adaptado)
A escola com maior nota no ranking nacional é dependência administrativa privada. A escola pública melhor colocada está apenas na 19o posição, sendo de dependência administrativa federal. A escola pública estadual melhor colocada no está na 101 ำ posição. Na região norte, a escola que obteve melhor nota ocupa a posição 3104. Observa-se a lacuna existente entre as escolas citadas anteriormente, localizadas em outras capitais do país (Fortaleza, Recife e Manaus), para a melhor colocada no universo desta pesquisa, que ocupa apenas a posição 9761 no ranking nacional (MEC, 2016).

Quadro 3- Ranking nacional com as notas do ENEM 2015
\begin{tabular}{|l|c|c|c|c|}
\hline Escola & $\begin{array}{l}\text { Posição } \\
\text { no } \\
\text { Ranking } \\
\text { Nacional }\end{array}$ & $\begin{array}{l}\text { Média } \\
\text { Geral }\end{array}$ & $\begin{array}{l}\text { Dependência } \\
\text { Administrativa }\end{array}$ & UF \\
\hline Farias Brito & 10 & 805,24 & Privada & CE \\
\hline $\begin{array}{l}\text { Colégio de } \\
\text { Aplicação da } \\
\text { UFV- Coluni }\end{array}$ & 19 o & 762,31 & Federal & MG \\
\hline $\begin{array}{l}\text { Escola de Apli- } \\
\text { cação do Recife }\end{array}$ & 101 - & 755,66 & Estadual & PE \\
\hline $\begin{array}{l}\text { EETI Mancanto- } \\
\text { nio Vilaca II }\end{array}$ & 3104 o & $631,8-$ & Estadual & AM \\
\hline $\begin{array}{l}\text { Esc. Est. Tira- } \\
\text { dentes }\end{array}$ & 97610 & 501,50 & Estadual & AP \\
\hline
\end{tabular}

Fonte: Mec, 2016 (Adaptado)

As escolas escolas estudadas que obtiveram os melhores rankings -Tiradentes, CCA e AVT- estão localizadas em regiões centrais, nos bairros Santa Rita, Central e Trem, respectivamente. As escolas que obtiveram as piores notas -Nilton Balieiro, Maria do Carmo e Profa Maria Cavalcante-, estão localizadas em regiões periféricas, nas zonas norte e oeste de Macapá. Um dos bairros 
onde está localizado a escola que tirou a segunda menor nota, é o segundo maior populoso da capital, possuindo 24.360 habitantes, (IBGE, 2010), e tem acesso apenas por vias de outro bairro (PALHETA; SANTOS; SERDOURA, 2016).

Em relação à situação econômica das escolas no que diz respeito a repasses federais para alimentação escolar, as escolas apresentam situação semelhante, com poucas variações. Observando o número de alunos e o quando é repassado para cada aluno, apenas uma escola apresenta uma variação positiva em relação às demais.

Tabela 1- Panorama de Repasses de Recursos

\begin{tabular}{lcc|c}
\hline Escola & $\begin{array}{c}\text { No de } \\
\text { Alunos }\end{array}$ & $\begin{array}{c}\text { Recurso Federal } \\
\text { em R\$ }\end{array}$ & \multicolumn{1}{c}{$\begin{array}{c}\text { R\$ por } \\
\text { Aluno }\end{array}$} \\
\hline Tiradentes & 472 & $70.773,90$ & 149,94 \\
CCA & 653 & $87.507,90$ & 134,00 \\
AVT & 279 & $89.986,80$ & 322,53 \\
Nilton & 170 & $32.789,60$ & 192,87 \\
$\begin{array}{l}\text { Maria do } \\
\text { Carmo }\end{array}$ & 173 & $17.445,80$ & 100,83 \\
$\begin{array}{l}\text { Maria Ca- } \\
\text { valcante }\end{array}$ & 184 & $37.790,30$ & 205,38 \\
\hline
\end{tabular}

Fonte: Secretaria de Educação do Estado do Amapá (2017)

Outros dados, como Indicador de formação Docente (IFD), que calcula a formação dos docentes que lecionam no ensino médio da escola, apresenta pouca variação. Apenas uma das escolas analisadas apresenta nível socioeconômico na categoria (Médio Alto). Em relação a taxa de abandono, uma das escolas apresenta um alto índice em relação às demais.

Tabela 2- Panorama Socioeconômico das escolas

Escola Nível Socioeconômico IFD TA

\begin{tabular}{llrr} 
Tiradentes & Médio Alto & 72,20 & 3,20 \\
CCA & Médio & 79,10 & 9,90 \\
AVT & Médio & 96,60 & 9,30 \\
Nilton & Médio & 76,60 & 26,10 \\
$\begin{array}{l}\text { Maria do } \\
\text { Carmo }\end{array}$ & Médio & 96,30 & 6,60, \\
$\begin{array}{l}\text { Maria Ca- } \\
\text { valcante }\end{array}$ & Médio & 76,20 & 9,30 \\
\hline
\end{tabular}

Fonte: MEC (2016)

\section{ANÁLISE E INTERPRETAÇÃO DOS DADOS}

Inicialmente, buscou-se entender a atuação do conselho escolar nas escolas. Para tanto, o primeiro questionamento direcionado aos gestores foi "Na sua escola existe conselho escolar? Se sim, como funciona a sua organização, quais são as suas atribuições e quem compõe o quadro?" As respostas apontaram que nas três escolas com melhores médias no ENEM, duas possuem o conselho escolar em sua estrutura e na outra, o conselho está em processo de formação e nas escolas com as piores médias, apenas uma possui o conselho escolar.

Quanto à composição do conselho escolar, os gestores afirmaram que há uma formação diversificada, como afirma o E6 "ele [conselho escolar] é formado por professores, funcionários da escola de diversos segmentos e a participação também de membros da comunidade". A respeito das atribuições, nos conselhos dessas escolas são debatidas questões de ordem financeira, estrutural e de ensino, como expõe o E3 “[...] discutem-se questões pedagógicas, relacionadas à aprendizagem de alunos, problemas que fogem do cotidiano da escola".

Com uma composição plural, envolvendo diversos atores ligados à escola, o conselho escolar torna-se não apenas uma estrutura 
de gestão para a tomada de decisões, mas representa um espaço para que a comunidade participe das decisões. A presença do conselho escolar está de acordo com o que Gracindo (2007) coloca, quando afirma que a gestão escolar deixa de ser prerrogativa apenas de uma pessoa, geralmente representada na figura do diretor, e passar a ser constituir como um trabalho coletivo, envolvendo segmentos escolares e comunidade local. Corroborando com o exposto, Brasil (2010) coloca que um dos princípios da gestão democrática, prescrito no Art. 14 da LDB, é a participação da comunidade local e escolar em conselhos escolares ou órgãos equivalentes.

Seguindo na linha de participação na gestão e nas decisões, a questão seguinte indagava "Na sua escola existe conselho de classe? Como o conselho atua dentro da instituição? Qual o seu papel na avaliação da aprendizagem?". De todas as escolas analisadas, apenas a que obteve maior média no ENEM apresenta a estrutura do conselho de classe. A atuação deste órgão na escola sucede quando, segundo o E1, "em determinadas situações, como falta de disciplina, índice baixo de aprendizagem". Esse fato está em concordância com Miranda (2014), onde afirma que essa é a função do conselho de classe, possibilitando a análise do desempenho da própria escola e dos alunos de forma coletiva. Nas demais escolas há apenas reuniões para tratar dessas questões relativas à aprendizagem.

Sendo o grêmio escolar um dos principais órgãos de participação e mobilização estudantil, questionou-se a cada entrevistado se "A escola possui um Grêmio Estudantil ou outro tipo de organização? Ele é atuante? Qual a sua contribuição para a instituição?". De acordo com as respostas, notou-se que apenas das duas primeiras colocadas no ranking do ENEM possuem esse tipo de estrutura. Em relação a atuação nessas escolas, o grêmio tem buscado levar a posição dos alunos quanto às questões de âmbito escolar, como afirma o E2 "É bem participativo, auxilia a escola, principalmente em problemas de indisciplina". Porém, apesar de proporcionar participação estudantil nas decisões da escola, o grêmio ainda carece de mais colaboração com a gestão, como apresentou o E1 "[...] fazem mais reinvindicação do que contribuição".

$\mathrm{Na}$ terceira colocada, há uma estrutura similar ao grêmio estudantil, onde a participação dos alunos nas decisões da escola acontece por meio dos representantes de turma. A ausência dessa estrutura nas demais escolas pode ser explicada pela falta de articulação estudantil, como explica o E3 "A escola tem que conceder o espaço, porém fica a cargo dos alunos se organizarem".

Com base no exposto, nota-se a participação mais efetiva das escolas que ocupam os primeiros lugares no ranking do ENEM, dado que as mesmas possuem uma estrutura que possibilita a presença dos alunos na gestão e tomada de decisão na escola. A presença de estruturas desse tipo na gestão corrobora com Silva (2014), quando argumenta que para uma adequada gestão democrática, deve haver espaços para os alunos se organizarem e defenderem seus interesses frente a gestão.

A questão seguinte questionou os gestores se "Existe dentro da instituição a Associação de Pais e Mestres (APM)? De que forma os pais dos alunos influenciam nas tomadas de decisão da escola?". Nenhuma das escolas entrevistadas conta com essa estrutura colegiada. A forma de participa- 
ção dos pais nas decisões da escola ocorre, de acordo com o E2 "os pais participam das decisões se dá por meio de reuniões nos plantões pedagógicos" ou como ocorre na escola do E3, quando afirma que "[...] esse papel da Associação de Pais e mestres está representado dentro do conselho escolar".

Assim como o conselho escolar, conselho de classe, grêmio estudantil, a APM também é um espaço colegiado onde os pais e mestres podem debater sobre questões presentes no cotidiano escolar e participar do processo de decisão. A ausência dessa estrutura nas escolas analisadas vai de encontro com o que Gonçalves (2012) coloca quando argumenta que a presença desse tipo de estrutura na unidade escolar contribui para a construção de uma nova escola, com face mais democrática, do modo como a requer.

O questionamento seguinte, perguntou aos gestores "Qual a participação dos pais e da comunidade escolar na elaboração do PPP da escola?". Identificou-se, por meio das respostas, unanimidade entre as escolas assim como na questão anterior (quando nenhuma escola apresentou a APM): em todas as seis escolas entrevistadas, há a participação dos pais e da comunidade escolar na construção do PPP. Na escola do E4, os pais "têm participação por meio de reuniões com sugestões de atividades, levantamentos e destinação de recursos.", assim como na escola do E6 "houve a participação da comunidade, a comunidade veio discutiu, opinou e apresentou sugestões para a elaboração desse projeto", do mesmo modo como ocorreu na escola do E2 "eles [os pais] deram suas opiniões a respeito dos projetos da escola".

Nota-se, portanto, que em todas as escolas analisadas, os pais e a comunidade par- ticipam da elaboração do projeto político pedagógico da escola, por meio de reuniões onde os pais podem opinar, debater, sugerir atividades para a escola. Essa participação é positiva, pois há a possibilidade de exposição de novas ideias e alternativas por uma visão diferente dos professores e gestores, além de está em concordância com o que Lück (2009) e Silva (2014) apresentam quando colocam que essas participação é essencial para tornar a escola um real espaço de promoção da educação, e deve ser incentivada visto que é um dos maior desafios a serem enfrentados pela gestão escolar pois exige compromisso e responsabilidade dos atores envolvidos.

Tratando-se da escolha do gestor, foi questionado aos entrevistados "De que forma são escolhidos os gestores da escola?". Assim como nas duas questões anteriores, todas as respostas foram iguais: os gestores são escolhidos por indicação política. O E6 relatou que "particularmente no nosso caso aqui, posso afirmar que não houve gerência política, não foi uma indicação política e sim questão técnica". Outro gestor, E1, afirma que busca mudar essa realidade "venho cobrando do conselho escolar para que haja uma eleição direta e posteriormente uma lista tríplice, para o governador escolher, que já seria um avanço".

Apesar está presente na legislação estadual por meio da Lei Complementar no 1.503 (2010) que trata sobre a gestão democrática no Amapá, a eleição direta para a escolha da equipe gestora deveria ser gerida pelo conselho escolar. Porém, nota-se que mesmos as escolas que apresentam a estrutura do conselho escolar, não a utilizam para escolha dos gestores. Isso está em discordância com o que Dourado (2012) 
argumenta sobre fazer uma gestão democrática, que implica em maior participação coletiva, tanto na elaboração do PPP e em decisões da escola, como na escolha dos gestores, que tradicionalmente baseiam-se no clientelismo por meio da livre indicação dos diretores pelos poderes públicos.

No que diz respeito a autonomia, foi questionado aos gestores se "A escola tem autonomia para decidir sobre seus objetivos, metas, formas organização e administração dos recursos financeiros?". Todos os entrevistados responderam que as escolas têm autonomia para desempenharem suas atividades pedagógicas, através dos projetos desenvolvidos pelos professores e gestores. Na parte financeira, os gestores alegaram que também há autonomia para decidir sobre sua utilização, como relatado pelo E3 "total autonomia. Recebemos e utilizamos acordo com as nossas necessidades" e E1 "temos autonomia para gerir esses recursos de maneira correta e de acordo com as necessidades da escola".

Uma das respostas de um dos entrevistados revelou que sua escola passa por dificuldades de ordem financeira, conforme relata o entrevistado E5 "Hoje nossa escola está inadimplente, porque outros gestores não prestaram contas". Percebe-se, que essa autonomia deve ser utilizada de modo adequado, observando os requisitos legais para tal, de modo a não direcionar a escola para o caminho relatado pelo entrevistado E5. As respostas dos gestores vão de encontro com o que está previsto na Brasil (2010), que assegura a autonomia para as escolas em graus progressivos, tanto de ordem pedagógica e administrativa, quando de gestão financeira.

As finanças constituem um importante papel na gestão de qualquer organização.
Desse modo, questionou-se aos gestores "Como é feita a alocação dos recursos financeiros na escola? Quais são os critérios utilizados?". As respostas revelaram que os recursos já vêm definidos pelos órgãos que os destinam. Como relata o E4 "Os recursos já vêm destinados, como por exemplo, a merenda e manutenção". O E2 esclarece quem destina esses recursos "Obedecem a instâncias superiores, como Ministério da Educação, recursos federais, custeio, projetos e manutenção".

A má alocação desse recurso pode causar sérios problemas para a gestão escolar, como ações e bloqueios judiciais, conforme relata o E6 "[...] a questão de administração desse recurso é um problema sério, nós hoje temos inúmeras ações de bloqueio do caixa escolar dadas a gestões passadas que não prestaram contas, que deixaram de recolher encargos sociais e dívidas com fornecedores", ainda segundo esse mesmo entrevistado "[...] o recurso cai mas a justiça bloqueia". Nota-se que tanto a escola do entrevistado $\mathrm{E} 5$ e entrevistado $\mathrm{E} 6$, que estão entre as que obtiveram as piores médias no ENEM dentre as entrevistadas, apontaram que suas escolas enfrentam problemas financeiros advindos pela má gestão dos recursos recebidos.

Acerca do setor financeiro e transparência, perguntou-se aos entrevistados "De que forma funciona a prestação de contas dos recursos financeiros?". As respostas revelaram que, institucionalmente, todo recurso recebido, seja estadual ou federal, deve ser prestado conta através no Núcleo de Prestação de Contas da Secretaria de Educação (NUPREC), onde nesse núcleo é realizada, de acordo com o E1, a "análise e emitido parecer para aprovação do TCE". Para a comunidade escolar, esse recurso é 
prestado contas de diversas formas, como afirma o E3 "Existe divulgação através de reuniões para a comunidade." e como cita o E4, por meio de uma "certidão de adimplência exposta no mural e sala dos professores".

Um caso preocupante à respeito dessa temática foi o relatado pelo E6 "Este ano por incrível que pareça ainda não foi feita a prestação de contas, dados a esses atropelos e essas dificuldades de bloqueios judiciais, é muito difícil trabalhar dessa forma.". Ainda segundo esse entrevistado "[...] do pouco recurso que sobra, nós vamos fazer a prestação de contas perante a comunidade.". Esse fato pode impactar indiretamente no ensino dessa escola, visto que a consequência da inadimplência é o bloqueio das contas judiciais, onde estão os recursos necessários para a escola colocar em prática seus projetos e garantir a alimentação adequada.

Uma das características mais marcantes da gestão democrática é a participação de diversos atores na gestão da escola. Nesse sentido, foi questionado aos gestores se "Os funcionários recebem algum tipo de incentivo, motivação? Se têm participação nas atividades da escola?". De acordo com as respostas, foi possível observar que há algum mecanismo de motivação e incentivo, como o explicitado pelo E4 "[...] procurando envolver todos, cada um nas suas especificidades, portaria de elogio", e pelo E1 "Através de projetos, eventos e portarias de elogios.". Outra forma de motivar os colaboradores é fazer com que eles se sintam parte da gestão, tendo responsabilidades e parcelas significativas no processo de tomada de decisão e essa é a forma que a escola do E6 busca realizar "[...] com os funcionários sempre se discute, é apresen- tado as dificuldades, dividir as responsabilidades.".

Sobre a divulgação, foi questionado aos gestores "Como a escola divulga seus resultados para a comunidade escolar?". Todos os entrevistados responderam que as escolas divulgam seus resultados por meio de reuniões, que é um mecanismo importante, segundo o E5, pois "[...] eles vêm para a escola, para ter mais contato com o aluno e comunidade, para eles poderem saber o que está acontecendo com a escola.". Outra forma de divulgação é por meio de mídias digitais, conforme relatou o E2 "Também há divulgação das informações pelo Facebook e blog.". Em uma das escolas que conta com a presença de órgãos colegiados, há a divulgação dos resultados da escola nesses ambientes, conforme afirma o E1 "Através do conselho escolar, que têm grupo, o grêmio também tem página, então há a constante divulgação.".

Desse modo, percebe-se que as escolas entrevistadas utilizam as reuniões como principal forma de exercer a transparência para a comunidade escolar, tanto dos recursos financeiros utilizados, como dos resultados pedagógicos, além de ser um espaço voltado para opiniões e sugestões. Isso vai ao encontro com o que Araújo (2000) expõe, quando diz que a transparência apresenta-se como um meio eficiente de dar credibilidade ao espaço público, ao oferecer à sociedade a participação da coisa pública.

A última questão buscou entender a percepção dos gestores sobre a relação entre gestão escolar e ENEM, desse modo, questionou-se aos mesmos "Na sua opinião, de que maneira a gestão escolar influencia no ENEM?". As respostas apontaram um maior entendimento da gestão escolar como elemento essencial para bom desempenho no 
ENEM por parte das três primeiras colocadas no Ranking. O E1 afirmou que "O nosso papel é cumprir aquilo que foi acertado, uma questão de organização. Os professores trazem as ideias para a coordenação, para buscar efetivar.". O E2 cita a gestão como base para um bom desempenho nesse exame, garantindo "Estruturação de ambiente [...], na garantia do cumprimento de um calendário, na garantia de ter professor para as turmas dos terceiros ano.".

Outro relato interessante, que abordou a gestão como primordial para traçar os caminhos a serem alcançados, foi o do gestor E3 "Ela [a gestão escolar] é fundamental, porque se não se tem uma organização, planejamento, você não obtém resultados, então nosso planejamento é feito antes de começar o ano letivo.". O E4 respondeu que a "gestão influencia, mas não consigo mensurar em porcentagem.". O E5 disse que "Através dos projetos a gestão pode influenciar no ENEM [...], procuramos saber qual é a deficiência dos alunos nas disciplinas.". O E6 relatou que "A gestão não pode agir sozinha, junto com o corpo docente teria que ter ações programadas e bem definidas para o ENEM.". Ainda segundo esse entrevistado "[...] Nós não temos um ensino médio que prepara para o ENEM por uma série de fatores e deficiências, nosso aluno não tem acesso a tudo que ele deveria ter.". Percebe-se, por meio das respostas, que os gestores das três primeiras escolas entendem e percebem bem a contribuição da gestão enquanto parte essencial para um bom desempenho no ENEM. Por outro lado, os gestores das três últimas escolas focaram suas respostas mais na gestão pedagógica, deixando um pouco de lado a gestão escolar.

A seguir será apresentado o Quadro 3 -
Comparativo Elementos da Gestão Democrática x Escolas contendo os elementos: participação, autonomia e transparência, compreendendo a quantidade de itens presentes nas escolas com melhores e piores notas, a fim de facilitar o entendimento acerca dos dados coletados.

A partir desses dados coletados, é possível perceber que a gestão democrática escolar exerce influência no desempenho no ENEM, principalmente nas dimensões de participação e transparência, onde as escolas com melhores notas apresentam diferenças sobre as escolas com piores notas, nos seguintes itens: conselho escolar, conselho de classe, grêmio estudantil, prestação de contas e divulgação dos resultados.

Quadro 3 - Comparativo Elementos da Gestão Democrática x Escolas

\begin{tabular}{|c|c|c|c|c|}
\hline \multirow{8}{*}{$\begin{array}{l}\text { GESTÃO } \\
\text { DEMO- } \\
\text { CRÁTICA }\end{array}$} & $\begin{array}{c}\text { ELEMEN- } \\
\text { TOS }\end{array}$ & ITENS & $\begin{array}{l}\text { MELHO- } \\
\text { RES }\end{array}$ & PIORES \\
\hline & \multirow[t]{5}{*}{$\begin{array}{l}\text { Participa- } \\
\text { ção }\end{array}$} & $\begin{array}{c}\text { Conselho } \\
\text { Escolar }\end{array}$ & $\begin{array}{c}2 \text { tem, } 1 \\
\text { formação }\end{array}$ & $\begin{array}{c}1 \text { tem, } 2 \\
\text { em forma- } \\
\text { ção }\end{array}$ \\
\hline & & $\begin{array}{l}\text { Conselho } \\
\text { de Classe }\end{array}$ & $\begin{array}{l}1 \text { tem, } 2 \\
\text { não tem }\end{array}$ & $\begin{array}{l}\text { Nenhuma } \\
\text { tem }\end{array}$ \\
\hline & & $\begin{array}{c}\text { Grêmio } \\
\text { Estudan- } \\
\text { til }\end{array}$ & $\begin{array}{l}2 \text { tem, } 1 \\
\text { não tem }\end{array}$ & $\begin{array}{l}\text { Nenhuma } \\
\text { tem }\end{array}$ \\
\hline & & $\begin{array}{c}\text { Escolha } \\
\text { dos } \\
\text { gestores }\end{array}$ & $\begin{array}{c}3 \text { por } \\
\text { indicação }\end{array}$ & $\begin{array}{c}3 \text { por } \\
\text { indicação }\end{array}$ \\
\hline & & $\begin{array}{l}\text { Partici- } \\
\text { pação na } \\
\text { elabora- } \\
\text { ção do } \\
\text { PPP }\end{array}$ & Reuniões & Reuniões \\
\hline & \multirow[t]{2}{*}{$\begin{array}{l}\text { Autono- } \\
\text { mia }\end{array}$} & $\begin{array}{c}\text { Alocação } \\
\text { de recur- } \\
\text { sos }\end{array}$ & $\begin{array}{l}\text { Todas } \\
\text { têm }\end{array}$ & Todas têm \\
\hline & & $\begin{array}{l}\text { Autono- } \\
\text { mia }\end{array}$ & $\begin{array}{l}\text { Todas } \\
\text { têm }\end{array}$ & Todas têm \\
\hline
\end{tabular}




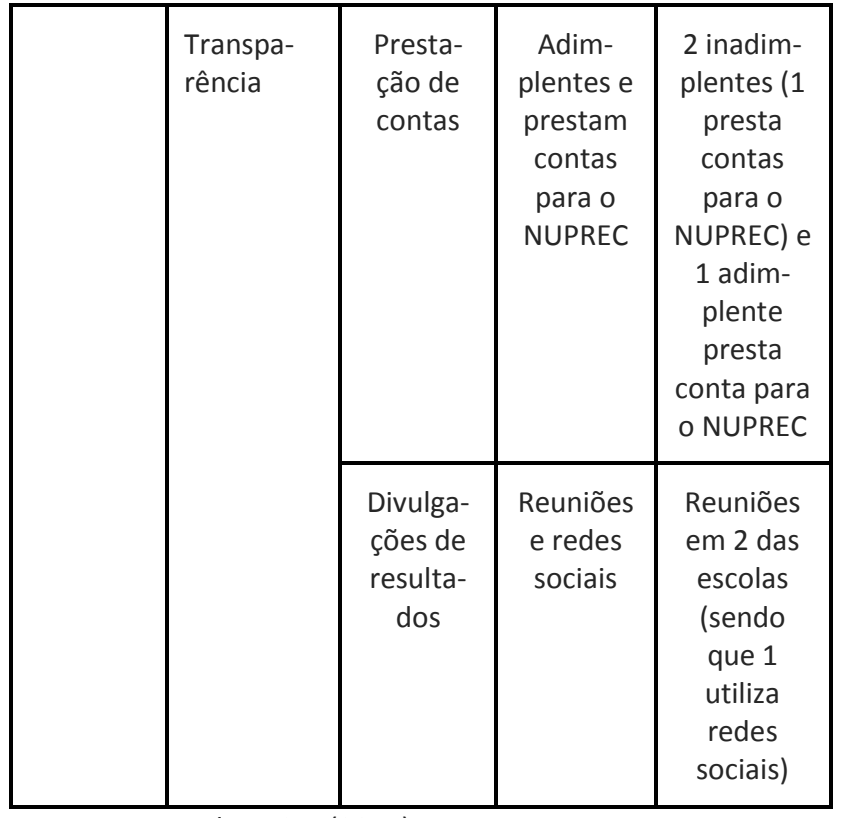

Fonte: autores do artigo (2017)

A partir desses dados coletados, é possível perceber que a gestão democrática escolar exerce influência no desempenho no ENEM, principalmente nas dimensões de participação e transparência, onde as escolas com melhores notas apresentam diferenças sobre as escolas com piores notas, nos seguintes itens: conselho escolar, conselho de classe, grêmio estudantil, prestação de contas e divulgação dos resultados.

\section{CONSIDERAÇÕES FINAIS}

A gestão democrática apresenta-se como uma forma de se gerir as instituições educacionais, proporcionando maior participação da comunidade local nas atividades e decisões da escola, maior autonomia e transparência das ações. Nesse sentido, este estudo buscou comparar as melhores e piores escolas, acordo com seu desempenho no ENEM, com base nos 4 (quatro) elementos da gestão democrática apresentados por Araújo (2000).

A importância deste trabalho está em fomentar a discussão sobre o ENEM, que atualmente tem grande relevância, sendo a principal forma de acesso para instituições públicas de ensino superior e em programas como o PROUNI, FIES; além de procurar relacionar o desempenho das escolas com a gestão escolar democrática.

De acordo com os quadros comparativos e com os resultados obtidos na pesquisa, através de entrevistas, é possível inferir que a gestão escolar democrática exerce influência no desempenho das escolas no exame, sendo que as escolas com as notas mais elevadas apresentam maiores níveis de participação e transparência.

As práticas exercidas pelos gestores nas escolas com melhores notas no exame, auxiliam ao aluno para que ele tenha um ambiente educacional favorável. Práticas essas exemplificadas em atividades e projetos voltados para o ENEM, maior liberdade para os alunos questionarem e sugerirem melhorias na instituição de ensino, maior participação da comunidade no âmbito escolar, bem como estar adimplente com seus deveres administrativos e financeiros, com intuito de receber os recursos em dia, e posteriormente, aplicá-los nos projetos educacionais.

Foi identificado também que as escolas de baixo desempenho no ENEM, apresentam dificuldades nas suas prestações de contas (recursos estaduais e federais), de modo a causar eventuais prejuízos que afetam direta e indiretamente os alunos nos projetos educacionais e merenda escolar. No que se refere a merenda, os alunos dessas escolas possuem quadro de aulas reduzido em decorrência da ausência de refeições. Com a quantidade de aulas reduzidas, é possível que exista a falta de absorção dos conteúdos com mais qualidade, o que traz 
prejuízo no seu ensino aprendizado.

Dentre os impasses encontrados, está a incompatibilidade de horários para realização de entrevistas com os gestores e docentes das escolas selecionadas, além das dificuldades de acesso e do curto período de gestão de alguns diretores/professores, 0 que ocasionou maior tempo de espera na coleta de dados.

Por fim, é importante mencionar que este trabalho não tem como propósito esgotar a discussão sobre as temáticas apresentadas, mas sim fomentar a discussão para trabalhos futuros.

\section{REFERÊNCIAS}

AMAPÁ. Lei Complementar n.1.503., de 09 de julho de 2010. Dispõe sobre a regulamentação da Gestão Democrática nas Unidades Escolares do Sistema Estadual de Ensino, prevista nos arts. 60 e 70 da Lei Estadual $n^{\circ} 0949$, de 26 de dezembro de 2005, bem como em observância ao disposto no inciso VI do art. 206 da Constituição Federal, Inciso II, do § 2ㅇ, do art. 285 da Constituição do Estado e ao inciso VIII do art. 3o da Lei $n^{\circ}$ 9.394/96 e dá outras providências. Amapá, Macapá, 09 jul.2010. ANDRIOLA, W. B.Doze motivos favoráveis à adoção do Exame Nacional do Ensino Médio (Enem) pelas Instituições Federais de Ensino Superior (Ifes). Ensaio: avaliação e políticas públicas em Educação. [online]. 2011, vol.19, n.70, p. 107-125.

ARAÚJO, Adilson César de. Gestão democrática da educação: a posição dos docentes. PPGE/UnB. Brasília. Dissertação de Mestrado, mimeog., 2000.

BOBBIO, Norberto. 0 futuro da democracia: uma defesa das regras do jogo. Rio de Janeiro: Paz e Terra, 2000.
BORDIGNON, Genuíno; GRACINDO, Regina Vinhaes. Gestão da educação: o município e a escola. In: FERREIRA, Naura Syria Carapeto; AGUIAR, Márcia Ângela da S. (Org.). Gestão da educação: impasses, perspectivas e compromissos. São Paulo: Cortez, 2000. p. 147-176.

BRASIL. Lei Complementar no 101, de 4 de maio de 2000. Estabelece normas de finanças públicas voltadas para a responsabilidade na gestão e dá outras providências. Brasília, DF. Recuperado em 10 de dezembro de 2016, de: <http://www.planalto.gov. $\mathrm{br} /$ ccivil 03/leis/LCP/Lcp101.htm>.

BRASIL. Constituição (1988). Constituição da República Federativa do Brasil. Brasília, DF, Senado, 1998.

BRASIL, [Lei Darcy Ribeiro (1996)]. LDBEN Lei de Diretrizes e Bases da Educação Nacional: Lei no 9.394, de 20 de dezembro de 1996, que estabelece as diretrizes e bases da educação nacional. 5.ed. Brasília: Câmara dos Deputados, Coordenação Edições Câmara, 2010.

CABRAL, Mozanilde Santos Nunes; SOUSA, Mônica Teresa; NASCIMENTO, Alberico Francisco. Estilos de liderança no contexto da gestão escolar democrática: algumas apreciações. Signos, ano 36, n. 2, p. 139149, 2015.

CASTRO, Maria Helena Guimarães; TIEZZI, Sergio. A reforma do Ensino Médio e a implantação do Enem no Brasil. In: Colin Brock \& Simon Schwartzman. (Org.). Os Desafios da Educação no Brasil. Rio de Janeiro: Nova Fronteira, 2005, v. , p. 119--151.

CERVO, Amado; BERVIAN, Pedro, A. Metodologia científica. 4. Ed. São Paulo: Makron Books, 1996.

CURY, Carlos Roberto Jamil. O Conselho Nacional de Educação e a Gestão Democrática. In: OLIVEIRA, Dalila Andrade (Org.). Gestão 
democrática da educação: desafios contemporâneos. Rio de Janeiro: Vozes, 1997. DOURADO, Luiz Fernando. Gestão em educação escolar. 4 ed. Cuiabá: Universidade Federal do Mato Grosso / Rede e-Tec Brasil, 2012.

FERNANDES, Cleudemar Alves. Análise do discurso: reflexões introdutórias. São Carlos: Editora Claraluz, 2008.

FREITAS, D. N. T. Avaliação e gestão democrática na regulação da educação básica brasileira: uma relação a avaliar. Educação \& Sociedade, v. 28, n. 99, p. 502, Ago. 2007. ISSN 0101-7330.

GONÇALVES, J. V. Participação do conselho de escola e APM no processo de administração/gestão democrática das Escolas Técnicas Estaduais (ETEs) da microrregião de Campinas. 87 f. Dissertação (Mestrado em educação). Centro Universitário Salesiano de São Paulo, Campinas-SP, 2012.

GRACINDO, R. V. Notas sobre a educação básica no PDE. Retratos da Escola, Brasília, DF, n. 1, 2007.

IBGE - Instituto Brasileiro de Geografia Estatística. Censo 2010. IBGE, 2010. Disponível em <http://www.ibge.gov.br/home/de fault.php>. Acesso em: 22 de Abril de 2018. $\mathrm{KLOH}$, Fabiana Ferreira Pimentel. Lei de Diretrizes e Bases da Educação Brasileira Comentada. 5a ed. Rio de Janeiro, Degrau Cultural, 2011.

KOETZ, C. M. Atuação da equipe diretiva e avaliações em larga escala: em busca de uma gestão democrática da escola pública. In: WERLE, F. O. C. (Ed.). Avaliação em larga escala: foco na escola. Brasília: Liber Livro, 2010.

LIBÂNEO, J. C. Organização e gestão da escola: teoria e prática. 5.ed. Goiânia: Alternativa, 2004.

LÜCK, Heloísa. Dimensões de gestão esco- lar e suas competências. Curitiba: Editora Positivo, 2009.

MARTINS, Marlúcia dos Santos Viana. A gestão escolar e a qualidade do ensino no Brasil. Anuário de produções acadêmicocientíficas dos discentes da faculdade Araguaia, v.3 . p. 250-273, 2015.

MATTAR, F. N. Pesquisa de marketing. 3.ed. São Paulo: Atlas, 2001.

MEC. Ministério da Educação/INEP. Sobre o Enem. Mec, 2016. Disponível em: <http:// portal.inep.gov.br/web/enem/sobre-o-ene m>. Acesso em: 03 de nov de 2016.

MENDES. Gilmar Ferreira. Da transparência, controle e fiscalização. MARTINS, Ives Gandra da Silva; NASCIMENTO, Carlos Vai der do (Org.). Comentários à Lei de Responsabilidade Fiscal. São Paulo: Saraiva, 2001. p. 335.

MIRANDA, N. A.. O Conselho de Classe como Instrumento de Avaliação da aprendizagem e Gestão Democrática na Escola Pública: um estudo de caso. In: IV Congresso Ibero Americano de Política e Administração da Educação, 2014, Porto. Anais do IV Congresso Ibero Americano de Política e Administração da Educação, 2014. v. 18. p. 1-16.

PALHETA. A. Corina; SANTOS, T. Brito; SERDOURA, F. Segregação ou integração dos espaços públicos urbanos: uma análise da zona norte de Macapá-AP. IN PLURIS, 2016, Maceió. Anais do Pluris, 2016. v1, p. 1-12. OLIVEIRA, João Ferreira; MORAES, Karine Nunes de; DOURADO, Luiz Fernandes. Gestão Democrática: definições, princípios e mecanismos de participação. In: Escola de Gestores da Educação Básica - MEC, CD1, 2008.

SEED - Secretaria de Estado da Educação/Ap. Relação de Repasse as Escolas. SEED, 2016. Disponível em: <https://seed.por 
tal.ap.gov.br/repasse.php?var=622>. Acesso em: 22 de Abril de 2018.

SILVA, Lucas Gomes; SACRAMENTO, Manuella Vieira. Gestão escolar democrática e sua inter(relação) com a qualidade da educação. InterletraS, V. 3, Edição número 21, de Abril, a Setembro 2015.

SILVA, Michele Pereira. A participação da comunidade na gestão democrática: Os mecanismos de participação. 2014. 68 f. TCC (Graduação) - Curso de Curso de Especialização em Gestão Escolar, Universidade de Brasília, Brasília, 2014.

SILVA, E. L.; MENEZES, E. M. Metodologia da pesquisa e elaboração de dissertação. 4. ed. Florianópolis, 2005.

TOURAINE, Alain. $\mathbf{O}$ que é a democracia?

Rio de Janeiro: Vozes, 1996.

VIEIRA, S. L. Política(s) e gestão da educação básica: revisitando conceitos simples. Revista Brasileira de Política e Administração da Educação, v. 23, n. 1, p. 53-69, jan-abr. 2007.

bVIEIRA, Sofia Lerche. Educação e gestão: extraindo significados da base legal. In. CEARÁ. SEDUC. Novos Paradigmas de gestão escolar. Fortaleza: Edições SEDUC, 2005, p. 7-20. 